\title{
PERSPECTIVAS DE ATUAÇÃO DO SECRETÁRIO EXECUTIVO NA GESTÃO DA INTERNACIONALIZAÇÃO DA EDUCAÇÃO SUPERIOR
}

\author{
PERSPECTIVES FOR THE EXECUTIVE SECRETARY IN THE MANAGEMENT \\ OF THE INTERNATIONALIZATION PROCESS IN HIGHER EDUCATION
}

\section{Fernanda Geremias Leal}

Doutoranda em Administração pela Universidade do Estado de Santa Catarina - Udesc, Florianópolis, (Brasil). Secretária Executiva da Secretaria de Relações Internacionais da Universidade Federal de Santa Catarina - UFSC, Florianópolis. E-mail: fernanda.leal@ufsc.br

\section{Mário Cesar Barreto Moraes}

Doutor em Engenharia de Produção pela Universidade Federal de Santa Catarina - Udesc, Florianópolis, (Brasil). Membro da Comissão Técnica de Acompanhamento da Avaliação do Instituto Nacional de Estudos e Pesquisas Educacionais Anísio Teixeira Legislação e Documentos - INEP/MEC - CTAA e Membro da Comissão de Avaliação de Projetos PET da Secretaria de Ensino Superior - SESU/MEC. É Presidente da Associação Nacional dos Cursos de Graduação em Administração - ANGRAD, Rio de Janeiro. E-mail: mcbmstrategos@ gmail.com 


\section{PERSPECTIVAS DE ATUAÇÃo DO SECRETÁRIO EXECUTIVO NA GESTÃo DA INTERNACIONALIZAÇÃO DA EDUCAÇÃO SUPERIOR}

\section{RESUMO}

A condição histórica e social do Brasil o situa em um campo de desafios epistêmicos. No contexto da educação superior internacional, esses desafios se manifestam na forma de passividade do Governo e das universidades públicas em relação às políticas e aos planos de internacionalização. Diante das necessidades de mudanças operacionais, estruturais e pragmáticas nas Instituições Federais de Ensino Superior (IFES) para lidar com as demandas da internacionalização e da quantidade significativa de profissionais de Secretariado Executivo que, na última década, têm atuado na gestão universitária, o propósito deste artigo é investigar se o secretário executivo apresenta competências que possam ser contributivas à gestão da internacionalização nas IFES. Desenvolveu-se uma pesquisa bibliográfica e documental, cuja primeira etapa consistiu no levantamento das competências necessárias à gestão da internacionalização, enquanto a segunda se pautou pela identificação das competências do secretário executivo, sobretudo as relacionadas ao contexto da gestão universitária. Elaborou-se um quadro conceitual comparativo dessas duas dimensões, que permitiu identificar a existência de relação teórica entre ambas. Inferiu-se que as competências do secretário executivo e sua migração de um campo operacional/mecanicista para um campo tático/estratégico o possibilitam contribuir para a gestão da integração das dimensões internacional, intercultural e global aos propósitos, às funções e à entrega da educação superior pública brasileira.

Palavras-Chave: Secretariado executivo; Educação superior; Gestão universitária. Internacionalização. 


\title{
PERSPECTIVES FOR THE EXECUTIVE SECRETARY IN THE MANAGEMENT OF THE INTERNATIONALIZATION PROCESS IN HIGHER EDUCATION
}

\begin{abstract}
The historical and social condition of Brazil places it in a field of epistemic challenges. In the context of international higher education, these challenges are manifested in government and public universities'passivity when it comes to internationalization policies and plans. Given the need for operational, structural and pragmatic changes in the Brazilian Federal Higher Education Institutions (IFES - Instituições Federais de Ensino Superior in Portuguese) to deal with the internationalization demands, and the significant number of executive secretariat professionals who, over the last decade, have worked in university management, the purpose of this paper is to investigate if the executive secretary has competencies that enable him/her to contribute to the internationalization management in the IFES. We developed a bibliographical and documentary research, of which first stage consisted in surveying the necessary competencies for the internationalization management, while the second was based on the identification of the executive secretariat professional competencies, especially those related to the university management context. We organized a comparative conceptual framework of these two dimensions, which allowed to visualize a theoretical relation between them. We inferred that the executive secretariat professional competencies and his/her migration of an operational/mechanical profile to a tactic/strategic one seems to enable him/her to contribute to the management of integration of the international, intercultural and global dimensions to the purposes, functions and delivery of the Brazilian public higher education.
\end{abstract}

Keywords: Executive Secretary; Higher education; University management; Internationalization. 


\section{INTRODUÇÃO}

Desde o início dos anos de 1990, com a crescente importância do conhecimento no desenvolvimento das economias e com o aumento da competitividade em nível global, a internacionalização universitária tem adquirido espaço nos planejamentos estratégicos institucionais e governamentais de todo o mundo, induzindo organizações e pesquisadores envolvidos com o setor educativo a anteciparem transformações definitivas nos diferentes sistemas nacionais de ensino superior (Knight, 2004, 2015; Childress, 2009; Lima \& Contel, 2011; Gacel-Ávila, 2012; Laus, 2012; Altbach \& De Wit, 2015).

Questões como a inclusão da cooperação internacional nos interesses da Conferência Mundial sobre Educação Superior da Organização das Nações Unidas para a Educação, a Ciência e Cultura (Unesco) (Unesco Brasil, 2003); a instituição de reformas voltadas à harmonização das políticas de educação superior em nível regional, como o Processo de Bologna (Azevedo, 2014); a constatação de que diversas universidades do mundo têm desenvolvido planos institucionais de internacionalização (Childress, 2009; Egron-Polak \& Hudson, 2014) e a supervalorização dos rankings universitários (Vieira \& Lima, 2015) demonstram que a abrangência, a escala e o valor desse conceito se ampliaram.

No Brasil, fatores como a adoção de critérios internacionais nas avaliações do Sistema Nacional de Pós-graduação (Capes, 2016); a instituição de programas governamentais de mobilidade internacional (como o Ciência sem Fronteiras) e de internacionalização em casa (como o Idiomas sem Fronteiras); a promoção de conferências sobre educação superior internacional (como a Faubai 2016 Conference); bem como a constatação de que todas as universidades públicas federais vinculadas à Associação Brasileira de Educação Internacional (Faubai) dispõem de setores responsáveis pelas gestão de atividades internacionais (Leal, Céspedes \& Stallivieri, 2016) sugerem que o país, tanto no nível institucional quanto no nível governamental, tem buscado acompanhar essa tendência.

A internacionalização diz respeito a um processo multifacetado, impulsionado por uma diversidade de motivações (acadêmicas, socioculturais, políticas e econômicas) e de caráter altamente circunstancial. Por desenvolver-se a partir de cada sistema educacional, com suas forças e fragilidades (Gacel \& Ávila, 2008), seus estágios e suas condições de manifestação diferenciam-se significativamente entre as realidades, o que intensifica sua complexidade (Knight, 2004). Uma das preocupações emergentes é que, sendo a 
internacionalização majoritariamente controlada pelo Norte, o Sul, aqui desvinculado de seu caráter geográfico e compreendido como campo de desafios epistêmicos, que procura reparar os danos e os impactos historicamente causados pelo capitalismo em sua relação colonial com o mundo (Santos \& Meneses, 2013), tende a inserir-se passivamente nesse meio, segundo uma lógica predominantemente reativa (Unesco Brasil, 2003; Lima \& Contel, 2011).

A condição histórica do Brasil o situa nesse campo de desafios epistêmicos e intensifica suas dificuldades de deliberação e de autonomia no contexto da internacionalização. Nesse sentido, em convergência à necessidade de estudos que contribuam para a descontinuidade dos processos de marginalização (Unesco Brasil, 2003; Morosini, 2006), é relevante compreender como as universidades brasileiras têm se preparado, em termos de competências, para lidar com as mudanças operacionais, estruturais e pragmáticas exigidas pela internacionalização (Childress, 2009; Hudzik, 2011).

Neste estudo, são analisadas especificamente as competências do profissional de Secretariado Executivo em relação às demandas de gestão da internacionalização das Instituições Federais de Ensino Superior (IFES). Trata-se de um profissional que, principalmente na última década, passou a integrar a administração dessas instituições (Ferreira, 2010; Pinheiro, 2013; Sousa, 2014; Leal, 2014; Raviani, 2015), muitas vezes atuando nos setores de relações internacionais (Bonzanini, 2010; Leal, 2014; Leal, Silva \& Dalmau, 2014, 2016), onde a gestão da cooperação internacional ocorre.

O propósito deste artigo é investigar se o secretário executivo apresenta competências que possam ser contributivas à gestão da internacionalização nas IFES. A proposta é identificar se, ao menos na teoria, esse profissional tem condições de ocupar um espaço significativo na gestão da integração das dimensões internacional, intercultural e global aos propósitos, às funções e à entrega da educação superior. Almeja-se, com isso, colaborar para a discussão sobre as possibilidades de atuação do secretário executivo e, simultaneamente, trazer uma reflexão acerca das competências requeridas à gestão de uma internacionalização autônoma e deliberativa nas IFES.

Apresenta-se um estudo bibliográfico e documental, cuja primeira etapa consiste no levantamento das competências identificadas na literatura como necessárias à gestão institucional da internacionalização da educação superior, enquanto a segunda se reporta à identificação, também bibliográfica e documental, das competências do secretário executivo, sobretudo no contexto da gestão universitária. 
O artigo está organizado da seguinte forma: inicialmente, apresentam-se considerações sobre as oportunidades e os desafios inerentes à internacionalização da educação superior, os obstáculos relativos à gestão institucional da internacionalização nos países do Sul e a inserção do secretário executivo na gestão das IFES, além de uma breve reflexão sobre a competência. Na sequência, detalham-se os procedimentos de levantamento bibliográfico e documental adotados, seguidos da análise e da discussão dos resultados obtidos. O texto finaliza com a exposição das considerações finais e das referências.

\section{REFERENCIAL TEÓRICO}

\subsection{Internacionalização da Educação Superior: Oportunidades e Desafios}

Aquilo que se entende por trocas científicas e culturais na educação superior não se refere a um fenômeno contemporâneo: uma breve retrospectiva histórica demonstra que uma dimensão internacional esteve presente nas universidades desde suas origens, tanto por conta da atuação de professores provenientes de diferentes partes do mundo, recrutados para dar início às primeiras atividades de ensino e pesquisa, quanto pela influência dos padrões internacionais de difusão do conhecimento (Miura, 2009; Altbach \& De Witd , 2015).

Foi somente na década de 1970, entretanto, que o termo internacionalização emergiu nesse contexto e no início dos anos de 1980 que ganhou popularidade (Knight, 2004, 2012; Laus, 2012). Os anos de 1990 representaram uma expansão da cooperação internacional na educação superior em velocidade sem precedentes. Com a difusão da globalização econômica, o conceito de internacionalização passou a ser referenciado como medida de qualidade e como recurso para que os sistemas educacionais respondam aos desafios de um contexto global complexo (Unesco Brasil, 2003; Hudzik, 2011; Gacel-Ávila, 2012; Altbach \& De Wit, 2015).

Knight (2004) oferece uma definição abrangente para internacionalização, com "generalidade suficiente por ser aplicável a diferentes países, culturas e sistemas educacionais" (Knight, 2004, p. 11, tradução nossa), ao considerá-la como o processo de integração das dimensões internacional, intercultural e global aos propósitos, às funções primárias e à entrega da educação superior nos níveis nacional e institucional. Segundo essa perspectiva, a internacionalização precisa ser compreendida nesses dois níveis, pois enquanto o setor nacional influencia substancialmente a dimensão internacional da educação superior, 
por meio de financiamento, políticas, programas e marcos regulatórios, é no nível institucional que o processo geralmente ocorre (Knight, 2004).

A internacionalização constitui-se, igualmente, como meio para alcançar um fim. Associa-se, dessa forma, a objetivos de natureza acadêmica, sociocultural, política ou econômica, os quais, com frequência, se complementam (Knight, 2004; Childress, 2009; Rudzik, 2011; Gacel-Ávila, 2012; Altbach \& De Wit, 2015). Em termos de objetivos acadêmicos institucionais, a internacionalização visa a contribuir para o aprimoramento da qualidade, da pertinência e da relevância da educação superior. Assim, por meio da experiência internacional, desenvolvem-se capacidades internas. Nas palavras de Sebastián (2004, p. 17, tradução nossa), a internacionalização é um recurso para

melhorar a qualidade, a pertinência e a relevância do ensino, da pesquisa e da extensão; articular a instituição no contexto mundial da educação superior; abrir novos espaços para a projeção internacional e a vinculação com redes acadêmicas internacionais; consolidar valores como a cooperação e a solidariedade na cultura institucional e ampliar as oportunidades de emprego aos egressos.

Entretanto, ainda que as oportunidades inerentes à internacionalização sejam múltiplas, suas consequências negativas e ameaças devem ser consideradas. Trata-se de um processo usado de diferentes formas, com distintas motivações (rationales), cujos estágios e condições de manifestação diferenciam-se significativamente entre as realidades. O surgimento de novos atores, novos programas e novas regulamentações revestem a educação superior contemporânea de complexidade (Knight, 2004; 2012; 2015).

Contradições como a ascensão das indústrias de certificação; a inserção de atores privados exclusivamente preocupados com o lucro; a emissão de títulos fraudulentos; a dependência de alguns países em relação a taxas de estudantes internacionais e a evasão de cérebros são exemplos de efeitos adversos da internacionalização (Unesco Brasil, 2003; Knight, 2004, 2012; Morosini, 2006; Altbach, 2012), os quais, em vez de aprimorar a qualidade da educação superior, criam ameaças para esse contexto. Uma forte pauta de discussão nessa conjuntura é a inclusão do setor educativo no Acordo Geral sobre Comércio e Serviços da Organização Mundial do Comércio (OMC), que, associada ao apoio inadequado do setor público à educação superior, tem contribuído para o estabelecimento de um ambiente internacional competitivo e voltado para o mercado, induzindo muitas universidades do mundo a comportarem-se como multinacionais (Unesco Brasil, 2003; Lima \& Contel, 2011).

Observa-se, portanto, que alguns dos interesses emergentes no domínio da educação superior internacional contemporânea parecem se contextualizar segundo uma perspectiva Revista de Gestão e Secretariado-GeSec, São Paulo, v. 8, n. 1, p 138-167,jan./abr. 2017. 
neoliberal, exclusivamente amparada no instrumentalismo econômico, em vez de associaremse a uma perspectiva de real aprimoramento da qualidade, da pertinência e da relevância do ensino, da pesquisa e da extensão (Lima \& Contel, 2011; Altbach, 2012). Como consequência, uma internacionalização cooperativa tem estado cada vez mais distante das agendas dos países que a protagonizam.

\subsection{Gestão Institucional da Internacionalização: Obstáculos às Universidades do Sul}

Os obstáculos existentes no contexto da internacionalização da educação superior tendem a ser mais evidentes nos países do Sul, cuja participação nesse processo obedece a uma lógica antes reativa do que deliberativa. Segundo Lima e Contel (2011), duas grandes limitações das nações semiperiféricas e periféricas as deixam em uma posição subordinada e agravam seu processo histórico de exclusão: a insuficiente cobertura educacional e a reduzida qualidade do ensino e da pesquisa.

Relativamente aos aspectos organizacionais das universidades desses países, pode-se mencionar como motivos de retardo as políticas e os planos estratégicos fragilizados, as limitações orçamentárias, as estruturas inadequadas dos escritórios de relações internacionais e a falta de pessoal técnico-administrativo bem preparado para lidar com esse fenômeno (Unesco Brasil, 2003; Gacel \& Ávila, 2008; Gacel-Ávila, 2012).

Um balanço do estado da educação superior na América Latina frente às demandas da internacionalização, feito por Gacel e Ávila (2008), ilustra essa realidade. Os autores constatam que as universidades desse subcontinente não se enquadram em um esquema definido, lógico e racional. Elas não alcançaram, ainda, um grau de avanço científico e tecnológico satisfatório e tampouco têm desempenhado plenamente seu papel social: a despeito do crescimento do número de matrículas e do maior acesso de estudantes com poucos recursos graças à educação pública, a desigualdade de oportunidades prevalece. Atrasos em nível de pós-graduação; deterioração das instalações; falta de atualização dos modelos pedagógicos e planos de estudo; importação de modelos desajustados contextualmente e escassez de recursos destinados à inovação, à pesquisa e à internacionalização são alguns dos problemas evidenciados (Gacel \& Ávila, 2008).

Relativamente à gestão universitária, Gacel e Ávila (2008) apontam deficiências tanto nas instituições privadas quanto nas públicas, sendo que no primeiro caso a forma gerencial predominante é centralizadora, com pouca participação docente, enquanto no Revista de Gestão e Secretariado-GeSec, São Paulo, v. 8, n. 1, p 138-167,jan./abr. 2017. 
segundo os gestores são escolhidos prioritariamente por forças políticas, o que, de modo geral, resulta em um alto nível de improvisação na gestão e inibe a participação social nas decisões. Gacel-Ávila (2012, p. 504, tradução nossa) complementa que os funcionários responsáveis pelas atividades internacionais geralmente apresentam baixo nível de profissionalismo e expertise, o que leva a uma "ausência de potencial para a concepção, desenho, implementação e promoção de políticas de estratégias de internacionalização".

Evidencia-se, portanto, que o processo de internacionalização se molda em função do comportamento de cada nação: enquanto alguns países centrais assumem papéis mais protagonistas, a maioria dos demais se insere nesse contexto de maneira subordinada (Lima \& Contel, 2011). Isso porque todo processo de internacionalização se constrói e se desenvolve a partir da situação de cada sistema educacional, com suas forças e fragilidades, que determinam o potencial e a viabilidade de suas estratégias (Gacel \& Ávila, 2008). A condição histórica do Brasil o situa nesse campo de desafios epistêmicos. No domínio da educação superior, questões estruturais em termos de acesso, equidade, qualidade e relevância, associadas a limitações relativas à gestão universitária (Gacel \& Ávila, 2008; Gacel-Ávila, 2012) intensificam suas dificuldades de deliberação e de autonomia na internacionalização.

Diante dessa conjuntura, é relevante compreender se as instituições universitárias brasileiras - sobretudo as públicas, cuja inserção nesse meio tende a distanciar-se de motivações econômicas diretas - dispõem de profissionais em seus quadros com competências que possam ser contributivas à gestão da integração das dimensões internacional, intercultural e global aos seus propósitos, às suas funções e à sua entrega.

\subsection{A Inserção do Secretário Executivo na Gestão das Instituições Federais de Ensino Superior}

O cargo de secretário executivo foi criado no contexto das Instituições Federais de Ensino Superior (IFES) durante o enquadramento do Plano Único de Classificação e Retribuição de Cargos e Empregos (PUCRCE). Na ocasião, os técnico-administrativos que desempenham funções típicas de Secretariado nessas instituições e que apresentaram diplomação de nível superior em quaisquer áreas do conhecimento foram beneficiados pela Lei n. 7.377/1985 (Brasil, 1985), que regulamenta a profissão, e passaram a ocupar o cargo (Leal, 2014; Leal, Silva \& Dalmau, 2014, 2016).

A autorização para a realização de concursos públicos para secretário executivo nas IFES veio com o Plano de Carreira dos Cargos Técnico-administrativos em Educação 
(PCCTAE), instituído pela Lei n. 11.091/2005 (Brasil, 2005). A partir desse momento, esse profissional, que atuava principalmente no setor privado, passou a integrar a gestão universitária pública federal em quantidade significativa. Em 2014, pelo menos 57 concursos para o cargo, em 48 IFES, já haviam sido realizados (Leal, Silva \& Dalmau, 2014, 2016). Nesse mesmo ano, 1.496 secretários executivos atuavam nessas instituições (Leal, 2014) e, em 2016, a quantidade se expandiu para 1690 (Souza, 2017).

A tabela 1, adaptada de MEC (2005), apresenta as atribuições prescritas para esse profissional no âmbito das IFES. Segundo a análise de Leal (2014), apesar de genéricas, essas atribuições não somente condizem com as leis que regulamentam a profissão, como parecem mais atualizadas e realistas em relação a estas, tendo em vistas as transformações evidenciadas no seu perfil.

Tabela 1: Atribuições do profissional de Secretariado Executivo nas IFES

\begin{tabular}{|c|c|}
\hline Atividade & Detalhamento \\
\hline Assessorar direções & $\begin{array}{l}\text { Administrar agenda pessoal das direções; despachar com a direção; colher assinatura; } \\
\text { priorizar, marcar e cancelar compromissos; definir ligações telefônicas; administrar } \\
\text { pendências; definir encaminhamento de documentos; assistir à direção em reuniões; } \\
\text { secretariar reuniões. }\end{array}$ \\
\hline Atender pessoas & $\begin{array}{l}\text { Recepcionar pessoas; fornecer informações; atender pedidos, solicitações e chamadas } \\
\text { telefônicas; filtrar ligações; anotar e transmitir recados; orientar e encaminhar pessoas; } \\
\text { prestar atendimento especial a autoridades e usuários diferenciados. }\end{array}$ \\
\hline $\begin{array}{l}\text { Gerenciar } \\
\text { informações }\end{array}$ & $\begin{array}{l}\text { Ler documentos; levantar informações; consultar outros departamentos; criar e manter } \\
\text { atualizado banco de dados; cobrar ações, respostas, relatórios; controlar cronogramas, } \\
\text { prazos; direcionar informações; acompanhar processos; reproduzir documentos; } \\
\text { confeccionar clippings. }\end{array}$ \\
\hline $\begin{array}{l}\text { Elaborar } \\
\text { documentos }\end{array}$ & $\begin{array}{l}\text { Redigir textos, inclusive em idioma estrangeiro; pesquisar bibliografia; elaborar relatórios; } \\
\text { digitar e formatar documentos; elaborar convites e convocações, planilhas e gráficos; } \\
\text { preparar apresentações; transcrever textos; taquigrafar ditados, discursos, conferências, } \\
\text { palestras, inclusive em idioma estrangeiro; traduzir em idioma estrangeiro, para atender às } \\
\text { necessidades de comunicação da instituição. }\end{array}$ \\
\hline $\begin{array}{l}\text { Controlar } \\
\text { correspondência }\end{array}$ & $\begin{array}{l}\text { Receber, controlar, triar, destinar, registrar e protocolar correspondência e } \\
\text { correspondência eletrônica }(e-m a i l) \text {; controlar malote. }\end{array}$ \\
\hline $\begin{array}{l}\text { Organizar eventos } \\
\text { e viagens }\end{array}$ & $\begin{array}{l}\text { Estruturar o evento; fazer check-list; pesquisar local; reservar e preparar sala; enviar } \\
\text { convite e convocação; confirmar presença; providenciar material, equipamentos e serviços } \\
\text { de apoio; dar suporte durante o evento; providenciar diárias, hospedagem, passagens e } \\
\text { documentação legal das direções (passaportes, vistos). }\end{array}$ \\
\hline $\begin{array}{l}\text { Supervisionar } \\
\text { equipes de trabalho }\end{array}$ & $\begin{array}{l}\text { Planejar, organizar e dirigir serviços de secretaria; estabelecer atribuições da equipe; } \\
\text { programar e monitorar as atividades da equipe. }\end{array}$ \\
\hline $\begin{array}{l}\text { Arquivar } \\
\text { documentos }\end{array}$ & $\begin{array}{l}\text { Identificar o assunto e a natureza do documento; determinar a forma de arquivo; } \\
\text { classificar, ordenar, cadastrar e catalogar documentos; arquivar correspondência; } \\
\text { administrar e atualizar arquivos. }\end{array}$ \\
\hline Outras atividades & $\begin{array}{l}\text { Utilizar recursos de informática e executar outras tarefas da mesma natureza e nível de } \\
\text { complexidade, associadas ao ambiente organizacional em que ele está inserido. }\end{array}$ \\
\hline
\end{tabular}

Fonte: Adaptada de MEC (2005).

Questões como a quantidade significativa de secretários executivos nas IFES, as transformações evidenciadas no seu perfil nas últimas décadas e a ausência de conhecimentos Revista de Gestão e Secretariado-GeSec, São Paulo, v. 8, n. 1, p 138-167,jan./abr. 2017. 
científicos sobre sua adequação a esse tipo de organização suscitaram o desenvolvimento de alguns artigos de periódicos e dissertações sobre o tema nos últimos dez anos. Tais pesquisas trataram dos seguintes aspectos: a) atuação e contribuições do secretário executivo na gestão universitária (Ferreira, 2010) e, especificamente, em unidades de ensino (Custódio, Ferreira \& Silva, 2008) e unidades administrativas das IFES (Bonzanini, 2010); b) condições de trabalho e qualidade de vida no trabalho do secretário executivo nas IFES (Oliveira, Minetti \& Oliveira, 2012; Pinheiro, 2013; Veiga \& Baptista, 2016); c) perfil, realidade laboral e panorama geral do secretário executivo nas IFES (Oliveira \& Moraes, 2014; Sousa, 2014; Souza, 2017); d) competências do secretário executivo nas IFES (Leal \& Fiates, 2013; Leal \& Dalmau, 2014; Leal, 2014; Raviani, 2015); e) motivações para ingresso do secretário executivo como servidor público das IFES (Faria \& Silveira, 2015) e f) concursos públicos para o cargo nas IFES (Leal; Silva \& Dalmau, 2014; Nunes, 2014; Oliveira et al., 2016);

Somente um desses trabalhos (Bonzanini, 2010) abordou especificamente a atuação do secretário executivo nos setores de relações internacionais de duas IFES, concentrando-se na sua função de mediador diante da inserção dessas instituições no contexto da globalização e relacionando alguns processos de trabalho desses setores nos quais ele pode propor melhorias. Apesar de suscitar importantes insights para estudos posteriores sobre o tema, o artigo não explora as perspectivas do secretário executivo na gestão da internacionalização no nível institucional, tendo como referencial a questão da competência. Nesse sentido, a presente pesquisa visa contribuir para o preenchimento dessa lacuna no campo teórico do Secretariado Executivo e, simultaneamente, trazer uma reflexão acerca das competências requeridas à gestão de uma internacionalização autônoma e deliberativa nas IFES.

\subsection{Breve Reflexão Sobre a Competência}

A perspectiva conceitual de competência adotada neste estudo é multidimensional: resulta da interação entre conhecimento (know-what e know-why), habilidade (know-how) e atitude como fatores interdependentes e necessários à consecução de determinado propósito, em um contexto específico (Durand, 2000; Brandão \& Bahry, 2005; Bergue, 2011).

O conhecimento - teórico, intermediário ou procedimental (Le Boterf, 2003) refere-se aos conjuntos estruturados de informações que são assimiladas pelo indivíduo e lhe possibilitam compreender o mundo diante de suas interpretações parciais e contradições (Durand, 2000). Habilidade, por sua vez - formalizada, experiencial ou cognitiva (Le Boterf, 
2003) - relaciona-se à capacidade de usar o conhecimento produtivamente; de agir concretamente, em concordância com objetivos predefinidos, mesmo quando não há um entendimento completo do motivo pelo qual as capacidades operacionalizadas funcionam. Portanto, está em parte associada a tacitividade e empirismo (Durand, 2000). Atitude, por fim - capacidade pessoal ou recurso emocional (Le Boterf, 2003) -, diz respeito ao comportamento resultante da determinação de um indivíduo ou de uma organização para conquistar algo. Em outras palavras, trata-se de "querer fazer"; de ter predisposição para exercer uma ação específica. Por isso, é fortemente influenciada pela cultura (Durand, 2000).

Essas três dimensões se inserem segundo uma relação de interdependência. Na visão de Durand (2000), não há construção de conhecimento sem ação; habilidade é vulnerável sem conhecimento e fraca sem capacidade para operar em grupo; atitude, por sua vez, é inútil sem significado e habilidade para a ação. Sob essa perspectiva, uma possível definição para competência é oferecida por Brandão e Bahry (2005, p. 180): “combinações sinérgicas de conhecimentos, habilidades e atitudes, expressas pelo desempenho profissional em determinado contexto ou em determinada estratégia organizacional”. Evidencia-se, dessa forma, que um indivíduo competente estará necessariamente apto a mobilizar tais dimensões no seu cotidiano para alcançar determinado resultado, que deverá agregar valor tanto para si próprio quanto para a organização (Fleury \& Fleury, 2001; Dutra, 2004).

Nessa linha, Fleury (2002) associa o termo competência aos verbos: saber agir (saber o que e por que fazer algo; saber julgar, escolher, decidir); saber mobilizar recursos (criar sinergia e buscar soluções); saber comunicar-se (conseguir compreender e transmitir informações e conhecimentos); saber aprender (usar conhecimentos e experiências; rever modelos mentais e se desenvolver); saber engajar-se e comprometer-se (saber empreender e assumir riscos; comprometer-se com os processos); saber assumir responsabilidades (responsabilizar-se pelos riscos e consequências de suas ações) e ter visão estratégica (entender o negócio e o ambiente da organização; identificar alternativas e oportunidades). Evidencia-se, assim, que a manifestação de competências engloba um conjunto de critérios, o que revela sua complexidade. $\mathrm{O}$ fato de um indivíduo ter capacidade para algo, entretanto, não implica benefício imediato para a organização. Por isso, Dutra (2004) associa o conceito de competência ao de entrega; àquilo que o indivíduo realmente deseja transpassar.

Os estudos contemporâneos demonstram que o conceito de competência não se limita a um estoque de conhecimentos teóricos e empíricos detidos pelo indivíduo e encapsulados na tarefa. Portanto, não pode ser reduzido a uma lista de atributos relacionados a 
um conhecimento ou a uma capacidade específica (Fleury \& Fleury, 2001; Fleury, 2002). Trata-se de um fenômeno complexo e multifacetado (Brandão \& Borges-Andrade, 2007; Brandão, Borges-Andrade \& Guimarães, 2012), que pode ser analisado e interpretado sob diferentes perspectivas (Bergue, 2011). Diz respeito, ainda, a um conjunto de aprendizagens sociais, à inteligência prática e à transformação dos conhecimentos adquiridos, que viabiliza o aumento do nível de complexidade das situações. Assim, está estritamente relacionado à aprendizagem e ao desenvolvimento.

\section{PROCEDIMENTOS METODOLÓGICOS}

Este estudo tem natureza descritiva e qualitativa e foi realizado por meio de duas etapas de levantamento bibliográfico e documental, em maio de 2016.

A primeira etapa consistiu no levantamento das competências consideradas pela literatura como necessárias à gestão da internacionalização institucional da educação superior. Neste momento, foram consultados artigos científicos, teses e dissertações sobre o tema, além de conteúdos programáticos de capacitações e de eventos promovidos por associações de educação internacional para profissionais da área. Essas associações são importantes atores no contexto da internacionalização, à medida que contemplam uma série de atividades que impulsionam esse processo, tais como: integração e cooperação regional; promoção de programas de mobilidade internacional para estudantes, professores e técnico-administrativos e oferta de capacitações/eventos sobre educação superior internacional. As bases utilizadas na coleta dos dados relativos à primeira etapa foram: Scopus (para artigos internacionais); Portal de Periódicos Capes (para artigos nacionais); Banco de Teses \& Dissertações Capes (para teses e dissertações nacionais) e Google (para capacitações e eventos sobre educação internacional). Os termos de busca utilizados na base Scopus foram: 1. Internationali?ation AND "higher education" AND management; 2. Internationali?ation AND "higher education" AND "international office"; 3. Internationali?ation AND "higher education" AND administration; 4. Internationali?ation AND "higher education" AND manager; 5. internationali?ation AND "higher education" AND competencies; 6. Internationali?ation AND "higher education" AND leadership. Os termos utilizados nas bases Portal de Periódicos Capes e Banco de Teses \& Dissertações Capes, por sua vez, foram: 1. internacionalização $A N D$ "educação superior". Neste último caso, optou-se por fazer uma 
busca mais ampla, tendo em vista a menor quantidade de estudos publicados no Brasil sobre internacionalização da educação superior.

A segunda etapa da pesquisa se reportou à identificação das competências do secretário executivo, sobretudo no contexto da administração universitária. Para tanto, foram consultados artigos científicos e dissertações sobre o tema, bem como as leis da profissão, as diretrizes curriculares para os cursos superiores de Secretariado Executivo e a descrição do cargo nas IFES. As bases utilizadas na coleta dos dados referentes à segunda etapa foram: Portal de Periódicos Capes e os cinco periódicos brasileiros mais receptivos ao diálogo direto com o campo teórico-empírico do Secretariado Executivo - Revista de Gestão e Secretariado; Capital Científico; Secretariado Executivo em Revista; Revista Expectativa e Fazu em Revista (para artigos nacionais) -; Banco de Teses \& Dissertações Capes (para teses e dissertações nacionais) e Google (para documentos relativos à profissão). Nesta etapa, optou-se por também pesquisar os artigos diretamente nos sítios dos periódicos, uma vez que poucos deles estão indexados às bases de dados. Os termos de busca utilizados nas bases Portal de Periódicos Capes e Banco de Teses \& Dissertações Capes foram: 1. "secretariado executivo" AND competência; 2. "Secretariado Executivo" AND universidade; 3. "Secretariado Executivo" AND "gestão universitária"; 4. "Secretariado Executivo" AND IFES. 5. "secretário executivo" AND competência; 6. "secretário executivo" AND universidade; 7. "secretário executivo" AND "gestão universitária"; 8. "secretário executivo" AND IFES.

Em ambas as etapas, não houve restrição temporal nas buscas. Os procedimentos de levantamento bibliográfico e documental são sintetizados na Tabela 2:

Tabela 2: Procedimentos de levantamento bibliográfico e documental

\begin{tabular}{|c|c|c|}
\hline Dados & Bases de coleta & fia analisada \\
\hline $\begin{array}{l}\text { Competências } \\
\text { necessárias à } \\
\text { gestão institucional } \\
\text { da } \\
\text { internacionalização }\end{array}$ & $\begin{array}{l}\text { - Scopus (artigos internacionais) } \\
\text { - Portal de periódicos Capes (artigos nacionais) } \\
\text { - Portal de teses \& dissertações Capes (teses e } \\
\text { dissertações nacionais) } \\
\text { - Google (capacitações e eventos sobre educação } \\
\text { internacional) }\end{array}$ & $\begin{array}{l}\text { - Teses, dissertações e artigos teóricos } \\
\text { e empíricos sobre o tema; } \\
\text { - conteúdos programáticos das } \\
\text { capacitações e dos eventos } \\
\text { promovidos por associações de } \\
\text { educação internacional. }\end{array}$ \\
\hline $\begin{array}{l}\text { Competências do } \\
\text { secretário } \\
\text { executivo, } \\
\text { sobretudo no } \\
\text { contexto da gestão } \\
\text { universitária }\end{array}$ & $\begin{array}{l}\text { - Portal de periódicos Capes (artigos nacionais) } \\
\text { - Periódicos nacionais mais receptivos ao diálogo } \\
\text { direto com o Secretariado Executivo (artigos } \\
\text { nacionais); } \\
\text { - Portal de teses \& dissertações Capes (teses e } \\
\text { dissertações nacionais); } \\
\text { - Google (documentos relativos à profissão). }\end{array}$ & $\begin{array}{l}\text { - Dissertações e artigos teóricos e } \\
\text { empíricos sobre o tema; } \\
\text { - legislação da profissão; } \\
\text { - diretrizes curriculares para os cursos } \\
\text { superiores de Secretariado } \\
\text { Executivo; } \\
\text { - descrição do cargo nas IFES. }\end{array}$ \\
\hline
\end{tabular}

Fonte: Elaborada pelos autores (2016). 
Além dos artigos, teses, dissertações e documentos resultantes das buscas sistemáticas, também foram utilizados os livros e as outras bibliografias utilizadas no referencial teórico.

A análise foi feita por meio do programa Excel, que permitiu a visualização e a exploração dos dados coletados em perspectiva ampla e comparada. $\mathrm{O}$ tratamento dos dados resultou no desenvolvimento de uma tabela conceitual com a sintetização das competências necessárias à gestão da internacionalização da educação superior no nível institucional e as competências do secretário executivo, segundo as referências consultadas, a fim de verificar se, na teoria, esse profissional apresenta competência que possam ser contributivas à gestão da internacionalização nas IFES.

\section{ANÁLISE E DISCUSSÃO DOS RESULTADOS}

As buscas sistemáticas contempladas na presente pesquisa permitiram evidenciar que, a despeito da crescente popularidade do conceito de internacionalização no contexto da educação superior e do consenso de que esse fenômeno tem transformado os sistemas educacionais e as estruturas universitárias (Hudzik, 2011; Gao, 2014; Knight, 2004, 2015), poucos estudos têm discutido a gestão institucional desse processo (Said et al., 2015; Stafford \& Taylor, 2016) ou as competências necessárias para esse fim. No Brasil, especificamente, não foram localizados quaisquer artigos de periódicos, teses ou dissertações com esses enfoques específicos. Apesar da ausência de pesquisas na área, diversas análises reconhecem a relevância da gestão universitária para o sucesso ou a falha da internacionalização (Stafford \& Taylor, 2016), uma vez que, se compreendido como processo de transformação institucional, esse processo implica mudanças operacionais, estruturais e pragmáticas, que demandam o desenvolvimento de políticas e a implementação de estratégias sustentáveis (Childress, 2009; Hudzik, 2011; Nafsa, 2015).

Os reitores/diretores e os setores de relações internacionais/indivíduos responsáveis pela gestão da internacionalização são apontados na literatura como os participantes internos que mais influenciam o desenvolvimento desse processo (internal key drivers) (Castro, Rosa \& Pinho, 2015). Os líderes institucionais exercem influência em todas as fases da sua institucionalização - conscientização, comprometimento, planejamento, operacionalização, revisão e monitoramento -, pois, com o seu suporte, emergem o apoio à captação de recursos para a execução de planos de internacionalização e a credibilidade para inserir componentes curriculares em tais planos (Childress, 2009). 
Uma questão colocada como relevante à gestão da internacionalização é a estrutura universitária, que deve proporcionar condições para lidar com a mudança e com os desafios inerentes a esse processo (Hudzik, 2011; Said et al., 2015). Said et al. (2015) constatam a demanda por uma unidade responsável por administrar e facilitar os assuntos relacionados à internacionalização, enquanto Hudzik (2011) menciona a necessidade de que esse setor esteja engajado às unidades acadêmicas, de apoio e de serviço. Isso porque a internacionalização abrangente requer o envolvimento de toda a comunidade universitária (Hudzik, 2011; GacelÁvila, 2012; Nafsa, 2015).

Cabe realçar que as atividades desenvolvidas por esses setores variam: enquanto alguns se limitam à gestão dos intercâmbios e ao apoio aos estudantes internacionais, outros se responsabilizam pelo estabelecimento de parcerias com instituições estrangeiras, administram centros de línguas/estudos culturais; buscam fontes de apoio e financiamento para pesquisa e projetos no exterior e impulsionam a internacionalização em casa (Hudzik, 2011; Gacel-Ávila, 2012). Leal, Céspedes e Stallivieri (2016) evidenciam que as atividades mais comuns aos setores de relações internacionais das IFES são a gestão de mobilidade internacional estudantil e a gestão de acordos/convênios de cooperação internacional.

Em termos de identificação das competências necessárias à gestão institucional da internacionalização, os esforços mais recentes são os da Association of International Educators (Nafsa, 2015). A partir dos feedbacks obtidos de especialistas sobre educação internacional e de dois mil profissionais da área, essa associação identificou as competências essenciais requeridas aos responsáveis pela execução direta dos serviços (equipe técnica), pela supervisão das operações das unidades (equipe de gestão em nível de coordenadoria) e pelos planejamentos estratégicos e decisões políticas (equipe de gestão em nível de direção), em relação àquilo que considera as cinco grandes áreas da gestão da educação internacional: a) internacionalização abrangente; b) educação no exterior; c) gestão de matrículas internacionais; d) serviços para a comunidade internacional; e) competências transversais.

Esses estudos revelam que a internacionalização da educação superior se refere, de fato, a um processo revestido de complexidade, que demanda uma série de competências técnicas e comportamentais, de caráter multidisciplinar, para sua institucionalização segundo uma perspectiva abrangente, visto que "o entendimento do processo de internacionalização da educação superior [...] não possui filiação disciplinar única” (Lima \& Contel, 2011, p. 14).

Os desafios relativos à gestão universitária são acentuados sobretudo nas universidades públicas dos países do Sul, que vivenciam questões estruturais internas que Revista de Gestão e Secretariado-GeSec, São Paulo, v. 8, n. 1, p 138-167,jan./abr. 2017. 
desfavorecem o desenvolvimento de processos ativos de internacionalização, a exemplo da escassez de recursos destinados à inovação, à pesquisa à internacionalização; a escolha de gestores universitários por forças políticas e o baixo nível de profissionalismo e expertise dos funcionários envolvidos com as atividades de natureza internacional (Gacel \& Ávila, 2008; Gacel-Ávila, 2012). Como Gacel-Ávila (2012) constata, esse quadro faz com que muitas vezes a intenção de internacionalizar não ultrapasse a retórica. Em suas palavras, "declarações feitas por autoridades educacionais sobre a importância da internacionalização são geralmente retóricas e raramente explicitam estratégias das mudanças necessárias ao desenvolvimento institucional” (Gacel-Ávila, 2012, p. 507, tradução nossa).

Relativamente à atuação do secretário executivo nos setores de relações internacionais das universidades e suas possíveis contribuições para a internacionalização, localizou-se o trabalho de Bonzanini (2010). Por meio de um estudo de caso nos setores de relações internacionais de duas IFES, a autora analisou sua função de mediador diante da inserção dessas instituições no contexto da globalização e relacionou alguns processos de trabalho desses setores nos quais ele pode propor melhorias, tendo em vista seu perfil profissional.

Outros estudos identificados sobre o profissional de Secretariado Executivo apontam para uma série de competências inerentes ao seu perfil que podem se constituir como contributivas à gestão da internacionalização nas IFES. É praticamente unânime o entendimento de que o elevado nível de complexidade e as organizações se submeteram nas últimas décadas induziu à aderência de novas competências, técnicas e comportamentais, a essa profissão. Assim, algumas das suas atribuições mais operacionais foram inteiramente reformuladas e cederam espaço à incorporação de outras mais significativas à gestão organizacional contemporânea. Considera-se, dessa forma, que o secretário executivo migrou de um campo operacional/mecanicista para um campo tático/estratégico. Com níveis elevados e autonomia e de espaço junto aos gestores, tornou-se apto a intervir nos processos decisórios; identificar dificuldades e solucioná-las; interpretar, analisar e criticar o ambiente em que está inserido e atuar como agente de mudanças (Bortolotto \& Willers, 2005; Duncan, 2014; Leal, 2014; Leal \& Dalmau, 2014, 2014a; Muller, Oliveira \& Cegan, 2015), inclusive no contexto da gestão universitária (Leal, 2014; Sousa, 2014).

Em termos de formação, o Secretariado Executivo se caracteriza como genérico e multidisciplinar. Integram seu currículo: conteúdos específicos da sua prática profissional (como técnicas secretariais), conteúdos de diferentes campos do conhecimento (como Administração, Línguas Estrangeiras, Contabilidade, Direito) e conteúdos de caráter 
humanístico (como Filosofia, Sociologia, Psicologia) (Maçaneiro \& Kuhl, 2013). O campo específico de Relações Internacionais também é contemplado pela formação (Leal, 2014).

Relativamente à atuação desse profissional nas IFES - contexto no qual o secretário executivo integrou-se na última década (Ferreira, 2010; Pinheiro, 2013; Sousa, 2014; Leal, 2014; Raviani, 2015), muitas vezes atuando nos setores de relações internacionais (Bonzanini, 2010; Leal, 2014; Leal, Silva \& Dalmau, 2014, 2016), onde a gestão da cooperação internacional ocorre - evidencia-se que algumas das atribuições prescritas para o cargo (MEC, 2005) vão diretamente ao encontro das demandas de internacionalização universitária. As seguintes podem ser apontadas: a) assessoria direta às direções do setor de relações internacionais - participantes internos influentes nesse quesito - por meio da qual o secretário executivo pode contribuir com todas as fases da institucionalização desse processo; b) prestação de atendimento especial a autoridades e a usuários diferenciados, considerando a necessidade de apoio a estudantes e professores em mobilidade internacional e o recebimento de visitas internacionais para o estabelecimento de parcerias; c) gerenciamento de informações, diante da necessidade de acompanhamento dos planos institucionais de internacionalização e de outros processos burocráticos, como convênios necessários para viabilizar a mobilidade acadêmica internacional; d) elaboração de textos em idiomas estrangeiros, tendo em vista as necessidades de comunicação com pessoas e instituições de outros países; e e) organização de eventos e viagens, considerando a necessidade de estruturação e de execução de eventos internacionais para divulgar oportunidades, bem como a realização de viagens para pessoas envolvidas com o contexto das relações internacionais tratarem de assuntos relativos à internacionalização.

Além das atribuições prescritas para o cargo, diversas outras competências inerentes ao perfil do secretário executivo, segundo as referências consultadas, puderam ser relacionadas ao contexto da gestão da internacionalização da educação superior. O tratamento dos dados coletados resultou no desenvolvimento de uma tabela conceitual comparativa, que sintetiza as competências necessárias à gestão da internacionalização da educação superior no nível institucional e as competências do secretário executivo, a fim de verificar se, na teoria, esse profissional apresenta competências que possam ser contributivas à gestão da internacionalização nas IFES. Portanto, a Tabela 3 consolida os resultados desta pesquisa: 
Tabela 3: Convergência entre as competências necessárias à gestão da internacionalização da educação superior e as competências do secretário executivo

\begin{tabular}{|c|c|}
\hline $\begin{array}{lllll}\begin{array}{l}\text { Competências necessárias } \\
\text { internacionalização }\end{array} & \text { à } & \text { gestão } & \text { da } \\
\end{array}$ & Competências do secretário executivo \\
\hline $\begin{array}{l}\text { Conhecimento geral sobre cultura, geografia, política, } \\
\text { história e economia de outros países; identificação e } \\
\text { articulação dos processos de ajustes culturais. } \\
\text { Compreensão histórica, filosófica e estrutural da } \\
\text { educação superior do seu país e do mundo. } \\
\text { Comunicação intercultural e sensibilidade; adaptação a } \\
\text { outras normas culturais quando apropriado. }\end{array}$ & $\begin{array}{l}\text { - Cultura geral; conhecimento sociocultural de países } \\
\text { estrangeiros; visão abrangente das mudanças do } \\
\text { mundo. } \\
\text { - Capacidade de adaptar-se a culturas e situações } \\
\text { variadas. }\end{array}$ \\
\hline $\begin{array}{l}\text { - Desenvolvimento, atualização, } \\
\text { acompanhamento de modelos, planos estraçãógicos, } \\
\text { políticas e procedimentos } \\
\text { internacionalização, que sejam condizentes com os } \\
\text { objetivos organizacionais e isentos de vieses culturais. }\end{array}$ & $\begin{array}{l}\text { - Elaboração de planejamentos estratégicos, relatórios, } \\
\text { prestações de contas, instruções técnicas; realização } \\
\text { de auditorias internas e de pesquisas; atualização de } \\
\text { bancos de dados; administração de arquivos; } \\
\text { elaboração, interpretação, sintetização e revisão de } \\
\text { textos profissionais especializados, inclusive em } \\
\text { idiomas estrangeiros. } \\
\text { - Gerenciamento e manutenção de fluxos de } \\
\text { informações destinadas à melhoria dos processos. } \\
\text { - Autonomia. }\end{array}$ \\
\hline $\begin{array}{l}\text { Condição de gerir pessoas; liderança. } \\
\text { Conhecimento de recursos para desenvolvimento e } \\
\text { aperfeiçoamento profissional na área de Educação } \\
\text { Internacional, para fins de capacitação da equipe de } \\
\text { Relações Internacionais. }\end{array}$ & $\begin{array}{l}\text { - Exercício de funções gerenciais, com domínio sobre } \\
\text { planejamento, organização, controle e direção; } \\
\text { supervisão de equipes; programação e } \\
\text { monitoramento das atividades da equipe. } \\
\text { - Compartilhamento de responsabilidades com o } \\
\text { gestor; organização dos recursos humanos e } \\
\text { materiais necessários; definição de metas e métodos } \\
\text { de trabalho; definições logísticas. } \\
\text { - Receptividade e liderança para o trabalho em equipe; } \\
\text { busca de sinergia; bom nível de relacionamento } \\
\text { interpessoal e intrapessoal. } \\
\text { - Necessidade de constante aprimoramento e aquisição } \\
\text { de novos conhecimentos. }\end{array}$ \\
\hline $\begin{array}{l}\text { Articulação, sensibilização, busca de apoio e } \\
\text { engajamento dos atores institucionais que influenciam o } \\
\text { processo de internacionalização; identificação de aliados } \\
\text { que possam ajudar na implementação de políticas e na } \\
\text { difusão da internacionalização. } \\
\text { Busca, avaliação, negociação e estabelecimento de } \\
\text { parcerias internacionais estratégicas e sustentáveis; } \\
\text { manutenção da comunicação com parceiros; } \\
\text { conhecimento da legislação referente ao } \\
\text { estabelecimento de acordos de cooperação recíprocos. }\end{array}$ & $\begin{array}{l}\text { - Comunicação, articulação e negociação com os } \\
\text { diversos níveis organizacionais para fins de } \\
\text { concretização de objetivos. } \\
\text { - Gerenciamento de informações institucionais } \\
\text { estratégicas, com uniformidade e referencial para } \\
\text { diferentes usuários. } \\
\text { - Coleta de informações para fins de consecução de } \\
\text { objetivos e metas organizacionais. } \\
\text { - Atuação como agente facilitador nas negociações e } \\
\text { na tomada de decisão; mediação de conflitos. }\end{array}$ \\
\hline $\begin{array}{l}\text { Ética (integridade, transparência, respeito às leis). } \\
\text { Responsabilidade social; respeito e defesa da } \\
\text { diversidade, da equidade e da inclusão; promoção de } \\
\text { condições de acessibilidade às minorias; comportamento } \\
\text { inclusivo; apreciação de múltiplas perspectivas; } \\
\text { envolvimento das comunidades locais no processo de } \\
\text { internacionalização. }\end{array}$ & $\begin{array}{l}\text { - Consciência das implicações e responsabilidades } \\
\text { éticas do exercício profissional. } \\
\text { - Responsabilidade socioambiental. }\end{array}$ \\
\hline $\begin{array}{l}\text { Qualidade e capacidade de resposta em relação aos } \\
\text { serviços prestados pelo setor de Relações Internacionais. } \\
\text { Compreensão do papel e da estrutura dos programas } \\
\text { internacionais. } \\
\text { Conhecimento do orçamento da instituição; pagamento } \\
\text { de bolsas para estudantes internacionais; transações }\end{array}$ & $\begin{array}{l}\text { - Identificação de oportunidades para melhorias do } \\
\text { setor; adoção de meios para o aperfeiçoamento dos } \\
\text { processos e produtividade dos serviços; domínio do } \\
\text { conteúdo técnico da área de atuação. } \\
\text { - Assessoramento direto a executivos; administração } \\
\text { de agendas; controle, organização e condução de }\end{array}$ \\
\hline
\end{tabular}

Revista de Gestão e Secretariado-GeSec, São Paulo, v. 8, n. 1, p 138-167,jan./abr. 2017. 


\begin{tabular}{|c|c|}
\hline financeiras internacionais. & $\begin{array}{l}\text { reuniões. } \\
\text {-Utilização do raciocínio lógico, crítico e analítico; } \\
\text { administração de recursos financeiros e materiais; } \\
\text { identificação das necessidades do setor e } \\
\text { equacionamento de soluções. }\end{array}$ \\
\hline $\begin{array}{l}\text { Conhecimento das tecnologias relevantes ao contexto da } \\
\text { Educação Internacional. }\end{array}$ & $\begin{array}{l}\text { - Habilidade de lidar com modelos inovadores de } \\
\text { gestão; utilização, maximização e otimização de } \\
\text { recursos tecnológicos. }\end{array}$ \\
\hline $\begin{array}{l}\text { Conhecimento de mecanismos de financiamento, } \\
\text { recursos e oportunidades; conhecimento das principais } \\
\text { tendências no campo da Educação Internacional; } \\
\text { promoção da visibilidade internacional da instituição; } \\
\text { participação em redes. }\end{array}$ & - Marketing organizacional. \\
\hline $\begin{array}{l}\text { Definição das melhores práticas de internacionalização } \\
\text { em casa. }\end{array}$ & $\begin{array}{l}\text { - Coordenação de projetos; implementação de ações } \\
\text { de gestão com vistas à consecução de metas. } \\
\text { • Atuação como agente de mudanças. }\end{array}$ \\
\hline $\begin{array}{l}\text { Capacidade de prestar aconselhamento e orientação } \\
\text { educacional internacional; divulgação de oportunidades } \\
\text { internacionais. } \\
\text { Ciência dos valores culturais e seus efeitos na interação } \\
\text { com pessoas e grupos e da influência da cultura e da } \\
\text { linguagem na aprendizagem. }\end{array}$ & $\begin{array}{l}\text { - Recepção; fornecimento de informações; } \\
\text { atendimento de pedidos e solicitações; orientação e } \\
\text { encaminhamento de pessoas. } \\
\text { - Atendimento especial a usuários diferenciados. }\end{array}$ \\
\hline Conhecimento de idiomas estrangeiros. & $\begin{array}{l}\text { - Prestação de serviços em idiomas estrangeiros; } \\
\text { tradução e versão. }\end{array}$ \\
\hline $\begin{array}{l}\text { Acompanhamento ou coordenação de missões oficiais } \\
\text { internacionais e recepção a visitantes estrangeiros; } \\
\text { organização de eventos para a elevação da dimensão } \\
\text { internacional da instituição; conhecimento de protocolos } \\
\text { internacionais. } \\
\text { Conhecimento dos regulamentos para obtenção de } \\
\text { vistos, seguros de saúde e custo de vida dos países. }\end{array}$ & $\begin{array}{l}\text { - Organização de viagens, eventos e visitas } \\
\text { internacionais; disponibilização de diárias, } \\
\text { hospedagens, passagens e documentação legal } \\
\text { (passaportes, vistos). } \\
\text { - Conhecimentos protocolares, inclusive de países } \\
\text { estrangeiros; atendimento especial a autoridades. }\end{array}$ \\
\hline $\begin{array}{l}\text { - Capacidade de inovar e lidar com constantes mudanças. } \\
\text { Habilidade de negociar e de lidar com imprevistos; } \\
\text { resolver emergências no exterior. }\end{array}$ & $\begin{array}{l}\text { - Criatividade, iniciativa, dinamismo, flexibilidade, } \\
\text { abertura a mudanças; capacidade de trabalhar sob } \\
\text { pressão; equilíbrio emocional; busca de soluções } \\
\text { para as diversas situações cotidianas. }\end{array}$ \\
\hline $\begin{array}{l}\text { Conhecimento sobre o que está acontecendo no campus } \\
\text { (especialmente no caso de instituição multicampi). } \\
\text { Conhecimento sobre internacionalização do currículo, } \\
\text { acreditação, avaliação e outros aspectos acadêmicos do } \\
\text { processo de internacionalização. }\end{array}$ & $\begin{array}{l}\text { - Conhecimento e visão geral da organização (missão, } \\
\text { cultura, valores, estrutura, atividades, hierarquia). } \\
\text { - Assessoria nas atividades de ensino, pesquisa e } \\
\text { extensão e execução de outras tarefas com nível de } \\
\text { complexidade condizente ao ambiente } \\
\text { organizacional em que o profissional está inserido. }\end{array}$ \\
\hline
\end{tabular}

Fonte: Elaborada pelos autores a partir de Unesco Brasil (2003); Knight (2004, 2012, 2015); MEC (2005,

2005a); Bortolotto \& Willers (2005); Scariot \& Durante (2008); Custódio, Ferreira \& Silva (2008); Childress (2009); Nafsa (2009, 2015, 2016); Bonzanini (2010); Ferreira (2010); Lima \& Contel (2011); Hudzik (2011); Lara (2012); Moreira \& Olivo (2012); Oliveira, Minetti \& Oliveira (2012); Maçaneiro \& Kuhl (2013); Pinheiro (2013); Leal \& Fiates (2013); Duncan (2014); Nunes (2014); Leal (2014); Leal \& Dalmau (2014, 2014a); Leal, Silva \& Dalmau (2014, 2016); Sousa (2014); Gao (2014); Oliveira \& Moraes (2014); Nascimento \& Silva (2015); Muller, Oliveira \& Cegan (2015); Monteiro, Cecatto \& Gardin (2015); Raviani (2015); Faria \& Silveira (2015); Castro, Rosa \& Pinho (2015); Said et al., (2015); Leal, Céspedes \& Stallivieri (2016); Faubai (2016); Oui-Iohe (2016), Eaie (2016); Stafford \& Taylor (2016); Veiga \& Baptista (2016); Oliveira et al. (2016); Souza (2017). 
Como a Tabela 3 demonstra, foi possível relacionar as competências necessárias à gestão da internacionalização da educação superior às competências do secretário executivo, sobretudo no contexto das IFES. Diversas convergências entre essas duas dimensões puderam ser identificadas. No geral, elas se referem aos seguintes aspectos: a) capacidade de adaptação cultural; b) gestão de políticas e de planejamentos estratégicos; c) gestão de pessoas; d) articulação e negociação com atores importantes e estabelecimento de parcerias sustentáveis; e) ética e responsabilidade social; f) administração dos recursos; g) condições de lidar com tecnologias; h) conhecimento do campo de atuação; i) coordenação de projetos; j) atendimento especializado; h) capacidade de prestação de serviços em idiomas estrangeiros; i) coordenação de eventos, visitas e viagens; j) capacidade de lidar com mudanças e lidar com imprevistos e k) conhecimento da estrutura e dos processos organizacionais.

Diante dos resultados obtidos, infere-se que, ao menos na teoria, o secretário executivo apresenta competências que podem ser contributivas à gestão da internacionalização dessas instituições. A interdisciplinaridade do seu perfil; os conteúdos específicos contemplados pela sua formação, a representatividade das suas funções em relação ao aperfeiçoamento da gestão universitária e sua caracterização como assessor, consultor, gestor e empreendedor contribuem para esse quadro e tornam sua perspectiva de atuação nesse contexto promissora. Em outras palavras, a internacionalização se evidencia como um fenômeno complexo e multifacetado e o perfil instituído ao profissional de Secretário Executivo parece acompanhar essa complexidade.

Assim, considerando-se as limitações relativas à gestão universitária dos países do Sul, que intensificam suas dificuldades de deliberação e de autonomia na internacionalização, compreende-se que o Secretariado Executivo que atua nos setores de relações internacionais das IFES pode representar um dos necessários contrapontos a essa passividade e contribuir com a gestão da integração das dimensões internacional, intercultural e global aos propósitos, às funções e à entrega da educação superior pública brasileira. Pressupõe-se que a atuação do secretário executivo no âmbito das relações internacionais das IFES pode constituir-se, inclusive, como fator de motivação para esse profissional, tendo em vista sua afinidade com questões de natureza internacional e a abrangência de conteúdos como idiomas estrangeiros na sua formação curricular.

Enfatiza-se que a tabela conceitual desenvolvida diz respeito a uma lista genérica, que serve como base para levantar afinidades entre as dimensões de interesse e suscitar o desenvolvimento de estudos empíricos a esse respeito, que tragam evidências mais concretas 
em relação às afinidades teóricas evidenciadas. Cabe mencionar, por fim, que cada instituição universitária apresenta particularidades oriundas do seu contexto e dos seus objetivos em termos de internacionalização, que exigirão competências específicas dos profissionais de Secretariado Executivo que atuam em seus ambientes.

\section{CONSIDERAÇÕES FINAIS}

Este artigo teve o propósito de investigar se o secretário executivo apresenta competências que possam ser contributivas à gestão da internacionalização nas IFES. Buscouse identificar se, ao menos na teoria, esse profissional tem condições de ocupar um espaço significativo na gestão da integração das dimensões internacional, intercultural e global aos propósitos, às funções e à entrega da educação superior. Almejava-se, com isso, colaborar para a discussão sobre as possibilidades de atuação do secretário executivo e, simultaneamente, trazer uma reflexão acerca das competências requeridas à gestão de uma internacionalização autônoma e deliberativa nas IFES.

A análise desenvolvida viabilizou a construção de uma tabela conceitual comparativa, por meio da qual se concluiu que, ao menos na teoria, o secretário executivo apresenta competências que podem ser contributivas à gestão da internacionalização dessas instituições. Trata-se de um profissional que tem se esforçado para ajustar seu perfil às necessidades organizacionais. Com isso, migrou de um campo operacional/mecanicista para um campo tático/estratégico. Sendo a internacionalização um processo multifacetado, impulsionado por uma diversidade de motivações, que envolve a formulação de políticas e a implementação de estratégias - e cuja complexidade se intensifica com a influência das políticas neoliberais no setor educativo - esse processo demanda mudanças operacionais, estruturais e pragmáticas nas universidades envolvidas. Tais instituições necessitam, portanto, de profissionais dotados de competências técnicas e comportamentais, capazes de atuarem como agentes de mudanças e cientes das oportunidades e dos desafios inerentes à internacionalização.

Ao familiarizar-se com os significados da internacionalização e de suas implicações para o contexto universitário, o secretário executivo pode direcionar esforços para seu aperfeiçoamento nesse campo, com vistas a desempenhar um papel significativo na busca pela melhoria da qualidade e da pertinência da educação superior no nível institucional. Dessa maneira, contribuirá tanto para a sustentabilidade da sua profissão quanto para a 
descontinuidade dos processos de marginalização que ocorrem nessa arena, dando apoio à busca por soluções criativas e à construção de modelos autônomos e deliberativos, voltados aos interesses legítimos de desenvolvimento do país. Diante da crise financeira global e da emergência de novas potências econômicas, o secretário executivo tem condições, por exemplo, de buscar parcerias estratégicas para cooperações dos tipos triangular e Sul-Sul, com inclusão social, em alternativa à tradicional cooperação Norte-Sul e, assim, ajudar a transformar a dinâmica da cooperação internacional no campo da educação superior.

Considerando-se que a convergência identificada é apenas teórica, depreende-se que estudos empíricos acerca da atuação do secretário executivo nos setores de relações internacionais das IFES poderão favorecer a compreensão do papel desse profissional no contexto da internacionalização da educação superior brasileira.

\section{REFERÊNCIAS}

Altbach, P. (2012). Corrupção: importante desafio à internacionalização. International higher education. Campinas: Unicamp.

Altbach, P. \& De Wit, H. (2015). Internationalization and global tensions: lessons from history. Journal of studies in international education, 19(1), 4-10.

Azevedo, M. (2014). The Bologna process and higher education in Mercosur: regionalization or europeanization? International Journal of Lifelong Education, 33(3), 411427.

Bergue, S. (2011). Modelos de gestão em organizações públicas: teorias e tecnologias para análise e transformação organizacional. Caxias do Sul: EDUCS.

Bonzanini, S. (2010). O profissional de secretariado executivo nas relações internacionais. Revista de Gestão e Secretariado (GeSec). São Paulo, 1(2), 143-162. jul./dez.

Bortolotto, M. \& Willers, E. (2005). Profissional de Secretariado Executivo: explanação das principais características que compõem o perfil. Revista Expectativa, 1(4). 
Brandão, H. \& Bahry, C. (2005). Gestão por competências: métodos e técnicas para o mapeamento de competências. Revista do Serviço Público, Brasília, 179-194, abr/jun.

Brandão, H. \& Borges-Andrade, J. (2007). Causas e efeitos da expressão de competências no trabalho: para entender melhor a noção de competência. Revista de Administração Mackenzie, 8(3), 32-40.

Brandão, H.; Borges-Andrade, J. \& Guimarães, T. (2012). Desempenho organizacional e suas relações com competências gerenciais, suporte organizacional e treinamento. Revista de Administração FEA-USP, 47(4), 523-539, out./nov./dez.

Brasil (1985). Lei n. 7.377, de 30 de setembro de 1985. Recuperado em 9 de maio, 2016 de < https://www.planalto.gov.br/ccivil_03/leis/17377consol.htm>.

. (2005). Lei n. 11.091, de 12 de janeiro de 2005. Recuperado em 9 de maio, 2016, de <http://www.planalto.gov.br/ccivil_03/_Ato2004-2006/2005/Lei/L11091.htm>.

Capes (2016). Sobre a avaliação. Recuperado em 9 de maio, 2016, de <http://www.capes.gov.br/avaliacao/sobre-a-avaliacao>.

Castro, R.; Rosa, M. \& Pinho, C. (2015). A model for stakeholders' influence on internationalization: a contribution from the Portuguese, Brazilian, and Dutch cases. Journal of studies in international education, 19(2), 160-181.

Childress, L. (2009). Internationalization plans for higher education institutions. Journal of studies in international education, 13(3). Fall.

Custódio, C.; Ferreira, F. \& Silva, L. (2008). O profissional de secretariado na gestão pública: um estudo de caso na faculdade de medicina da Universidade Federal do Ceará (UFC). Secretariado Executivo em Revista.

Duncan, M. (2014). The case for executive assistants. Harvard Business Magazine. Boston: Harvard University Press.

Revista de Gestão e Secretariado-GeSec, São Paulo, v. 8, n. 1, p 138-167,jan./abr. 2017. 
Durand, T. (2000). Forms of incompetence. In: Sanchez, R. \& Heene, A. Theory development for competent-based management. Greenwich: JAI Press.

Dutra, J. (2004). Competências: conceitos e instrumentos para a gestão de pessoas na empresa moderna. São Paulo: Atlas.

Eaie (2016). EAIE 2016: Programme. Recuperado em 9 de maio, 2016, de $<$ http://www.eaie.org/liverpool/programme.html>.

Egron-Polak, E. \& Hudson, R. (2014). Internationalization of higher education: growing expectations, fundamental values. IAU $4^{\text {th }}$ Global Survey, IAU.

Faria, E. \& Silveira, T. (2015). Os fatores que influenciam os egressos do curso de Secretariado Executivo trilíngue da Universidade Federal de Viçosa a ingressarem no serviço público. Revista de Gestão e Secretariado (GeSec), 6(1), 48-73, jan./abr.

Faubai (2016). Faubai 2016 Conference: Full program. Recuperado em 9 de maio, 2016, de < http://www.faubai.org.br/conf/2016/program/>.

Ferreira, F. (2010). A atuação do secretário executivo no setor público: o caso da Universidade Federal do Ceará. Dissertação de mestrado, UFC, Fortaleza.

Fleury, M. \& Fleury, A. (2001). Construindo o conceito de competência. Revista de administração contemporânea. Edição Especial, 183-196.

Fleury, M. (2002). A gestão de competência e a estratégia organizacional. In: Fleury, M. (org.). As pessoas na organização. São Paulo: Editora Gente.

Knight, J. (2004). Internationalization remodeled: definition, approaches, and rationales. Journal of studies in international education, 1(1). 5-31. Spring.

. (2012) Student mobility and internationalization: trends and tribulations. Research in comparative \& international education. 7(1).

Revista de Gestão e Secretariado-GeSec, São Paulo, v. 8, n. 1, p 138-167,jan./abr. 2017. 
. (2015). International universities: misunderstandings and emerging models? Journal of Studies in International Education, 1-15.

Gacel, J. \& Ávila, R. (2008). Universidades latinoamericanas frente al reto de la internacionalización. Casa del Tiempo. jul.

Gacel-Ávila, J. (2012). Comprehensive internationalisation in Latin America. Higher Education Policy, 25, 493-510.

Gao, Y. (2014). Toward a set of internationally applicable indicators for measuring university internationalization performance. Journal of studies in international education, 119.

Hudzik, J. (2011). Comprehensive internationalization: from concept to action. New York: Nafsa.

Lara, R. (2012). Propuesta para competencias profesionales de um director de relaciones internacionales de una universidad em el siglo XXI. In Lara, R. \& Stallivieri, L. La internacionalización y la cooperación universitaria. Argentina: RLCU.

Laus, S. (2012). A internacionalização da educação superior: um estudo de caso da Universidade Federal de Santa Catarina. Tese de doutorado, Salvador, UFBA.

Le Boterf, G. (2003). Desenvolvendo a competência dos profissionais. Porto Alegre: Artmed.

Leal, F. (2014). Competências secretariais requeridas pela UFSC. Dissertação de mestrado, Florianópolis: UFSC.

Leal, F. \& Dalmau, M. (2014). Análise das competências secretariais requeridas pela UFSC em comparação ao perfil profissiográfico do secretário executivo. Revista de Gestão e Secretariado. São Paulo, 5(3). 143-174. set./dez. 
. (2014a). Formação e perspectivas de atuação do secretário-executivo no Brasil. Revista do Secretariado Executivo, 10, 71-85.

Leal, F. \& Fiates, G. (2013). Competências dos secretários executivos de uma universidade pública federal: uma análise a partir da perspectiva dos gestores. Revista de Gestão e Secretariado, 4(3), 30-57, dez.

Leal, F.; Silva, A. \& Dalmau, M. (2014). Análise das avaliações dos concursos públicos realizados pelas IFES para o cargo de secretário-executivo sob a ótica da Gestão por Competência. Revista de Ciências da Administração, 191-207, dez.

_ـ (2016). Recrutamento e seleção por competências para o cargo de secretárioexecutivo. XL Encontro da Anpad. Costa do Sauípe: Anpad.

Leal, F.; Céspedes, R. \& Stallivieri, L. (2016). O perfil do gestor universitário de cooperação internacional frente ao desafio da internacionalização da educação superior. Faubai 2016 Conference. Fortaleza.

Lima, M. \& Contel, F. (2011). Internacionalização da educação superior: nações ativas, nações passivas e a geopolítica do conhecimento. São Paulo: Alameda.

Maçaneiro, M. \& Kuhl, M. (2013). Estado da arte e rumo do conhecimento científico em Secretariado Executivo: mapeamento e análise de áreas de pesquisa. Revista de Gestão e Secretariado. São Paulo, 4(3), 157-188, dez.

Miura, I. (2009). O processo de internacionalização da Universidade de São Paulo: um estudo em três áreas do conhecimento. XXXIII Encontro da ANPAD. São Paulo: Anpad.

Morosini, M. (2006). Estado da arte sobre internacionalização da educação superior: conceitos e práticas. Educar em Revista, 28, jul.-dez., 107-124.

MEC (2005). Ofício n. 15/2005/CGGP/SAA/SE/MEC, de 28 de novembro de 2005. Descrição dos cargos técnico-administrativos em educação. Brasília: Ministério da Educação. 
. (2005a). Resolução n. 3, de 23 de junho de 2005. Brasília: Ministério da Educação.

Monteiro, C.; Cecatto, Q. \& Gardin, D. (2015). O profissional de Secretariado e a responsabilidade socioambiental: a importância da assessoria executiva. Revista de Gestão e Secretariado, São Paulo, 6(2), 134-157, maio/ago.

Moreira, K. \& Olivo, L. (2012). O profissional de Secretariado como mediador de conflitos. Revista de Gestão e Secretariado. São Paulo, 3(1). 30-53, jan./jun.

Muller, R.; Oliveira, V. \& Cegan, E. (2015). Perfil do profissional de Secretariado Executivo na gestão contemporânea. Revista de Gestão e Secretariado, 6(3), 129-151, set./dez.

Nafsa (2009). Statement of ethical principles. Washington: Nafsa.

. (2015). NAFSA International education professional competencies. Washington: Nafsa. . (2016.) NAFSA 2016 Annual conference \& expo: program. Recuperado em 9 de maio, 2016, de <http://www.nafsa.org/Attend_Events/Annual_Conference/Educational_Offerings/>.

Nascimento, H. \& Silva, K. (2015). O secretário executivo bilíngue como agente facilitador em negociações do Mercosul. Revista de Gestão e Secretariado. 6(3). set./dez., 117-128.

Nunes, W. (2014). Concurso público: uma análise dos editais no processo seletivo de secretários executivos nas instituições federais de ensino. Revista do Secretariado Executivo, $10,105-118$. 
Oliveira, P.; Minetti, L. \& Oliveira, L. (2012). Qualidade de vida no trabalho: um enfoque no profissional de Secretariado Executivo de uma instituição federal de ensino superior. Revista de Gestão e Secretariado, 3(2), 87-105, jul./dez.

Oliveira, L. \& Moraes, G. (2014). O panorama do cargo de Secretário Executivo em uma instituição federal de ensino superior e as implicações da Lei n. 11.091/2005. Revista de Gestão e Secretariado, 5(2), 49-71, maio/ago.

Oliveira, L.; Soares, M.; Oliveira, L. \& Paula, N.. (2016). Os concursos para o cargo de Secretário Executivo nas instituições federais de ensino superior. Revista de Gestão e Secretariado, 7(3), 202-225, set./dez.

Oui-Iohe (2016). Diploma em internacionalização da educação superior. Recuperado em 9 de maio, 2016, de <http://www.oui-iohe.org/pt/servicos-oui/atividades-deinternacionalizacao/diploma-em-internacionalizacao-do-ensino-superior/>.

Pinheiro, V. (2013). Condições de trabalho do profissional de Secretariado Executivo no setor público: um estudo de caso na Universidade Federal do Ceará. Dissertação de mestrado, Fortaleza, UFC.

Raviani, C. (2015). Competências individuais: secretários executivos das universidades federais do estado de São Paulo. Dissertação de mestrado, Osasco, Unifesp.

Said, H.; Ahmad, I.; Mustaffa, M. \& Ghani, F. (2015). Role of campus leadership in managing change and challenges of internationalization of higher education. Mediterranean Journal of Social Sciences, 6(4), july.

Santos, B. \& Meneses, M. P. (2013). Epistemologias do Sul. São Paulo: Cortez Editora.

Scariot, T. \& Durante, D. (2008). Comércio internacional: uma perspectiva profissional ao secretário executivo. Secretariado Executivo em Revista. 4. 
Sebastián, J. (2004). Cooperación e internacionalización de las universidades (1a ed.). Buenos Aires: Biblos.

Sousa, E. (2014). Perfil e realidade laboral do Secretário Executivo no contexto das universidades públicas federais brasileiras. Dissertação de mestrado,. Florianópolis: UFSC.

Souza, S. (2017). O quadro de pessoal do cargo de secretário executivo na Universidade Federal de Santa Catarina. Dissertação de mestrado, Florianópolis: UFSC.

Stafford, S. \& Taylor, J. (2016). Transnational education as an internationalisation strategy: meeting the institutional management challenges. Journal of higher education policy and management, 38(6), 625-632.

Unesco Brasil (2003). Educação superior: reforma, mudança e internacionalização. Anais. Brasília: Unesco Brasil, Sesu/MEC.

Veiga, F. \& Baptista, E. (2016). Intensificação e precarização do trabalho de técnicoadministrativos na UFPA: um estudo sobre o trabalho dos secretários. Revista Expectativa, $15(15), 1-23$.

Vieira, R. \& Lima, M. (2015). Academic rankings: from its genesis to its international expansion. Higher Education Studies, 5(1), 63-72. 